\title{
Comparison of flexible, open with semi- rigid, closed annuloplasty-rings for mitral valve repair
}

\author{
Ayse Cetinkaya', Maryam Waheed ', Karin Bramlage², Oliver Johannes Liakopoulos ${ }^{1}$, Mohamed Zeriouh', \\ Stefan Hein ${ }^{1}$, Peter Bramlage ${ }^{2}$ (D), Markus Schönburg ${ }^{1}$, Yeong-Hoon Choi ${ }^{1 *}$ and Manfred Richter ${ }^{1}$
}

\begin{abstract}
Background: Mitral regurgitation is a frequent valvular disease, with an increasing prevalence. We analysed the long-term outcomes of mitral valve repair procedures conducted over the last 10 years in our clinic using almost exclusively two different annuloplasty ring types.

Methods: A single-centre, retrospective analysis of mitral valve surgeries conducted between January 2005 and December 2015 for patients undergoing first-line mitral valve repair with either open (Cosgrove) or closed (CE Physio / Physio II) annuloplasty (OA or CA, respectively) rings.

Results: In total, 1120 patient documentations were available of which 528 underwent OA and 592 patients CA. The median age of patients was 64.0 years and $41.1 \%$ were female. The majority of these patients underwent the procedure because of degenerative valve disease. Rates of successful repair were about $90 \%, 72 \mathrm{~h}$ procedural mortality was $0.6 \%$ and the rate of re-intervention was $0.6 \%$ within the first 30 days. Functional (mitral regurgitation, left ventricular ejection fraction, left ventricular end-diastolic and systolic diameter and New York Heart Association class) as well as hard outcomes were comparable. 77.7 and $74.4 \%$ of patients were alive at the 10-year follow-up in the OA and CA groups, respectively. Upon multivariable adjustment, the hazard ratio was 0.926 ( $95 \%$ Cl: $0.642-$ $1.3135 ; p=0.681)$.

Conclusions: The functional outcome and survival rates up to 10 years after mitral valve repair were comparable using open and closed annuloplasty rings. Whether this means these rings are interchangeable or a carefully selection of the best-for-the-patient devices will be subject of future investigations.
\end{abstract}

Keywords: Mitral valve repair, Mitral regurgitation, Annuloplasty, Open ring, Closed ring

\footnotetext{
* Correspondence: y.choi@kerckhoff-klinik.de

'Department of Cardiac Surgery, Kerckhoff-Heart Center Bad Nauheim,

Campus of the University Hospital Giessen, Justus-Liebig Universiy Giessen, Benekestraße 2-8, 61231 Bad Nauheim, Germany

Full list of author information is available at the end of the article
}

(c) The Author(s). 2021 Open Access This article is licensed under a Creative Commons Attribution 4.0 International License, which permits use, sharing, adaptation, distribution and reproduction in any medium or format, as long as you give appropriate credit to the original author(s) and the source, provide a link to the Creative Commons licence, and indicate if changes were made. The images or other third party material in this article are included in the article's Creative Commons licence, unless indicated otherwise in a credit line to the material. If material is not included in the article's Creative Commons licence and your intended use is not permitted by statutory regulation or exceeds the permitted use, you will need to obtain permission directly from the copyright holder. To view a copy of this licence, visit http://creativecommons.org/licenses/by/4.0/ The Creative Commons Public Domain Dedication waiver (http://creativecommons.org/publicdomain/zero/1.0/) applies to the data made available in this article, unless otherwise stated in a credit line to the data. 


\section{Background}

Primary mitral regurgitation (MR) is the result of pathology affecting at least one component of the mitral valve apparatus and is usually the consequence of degenerative disease. Surgical intervention is associated with high repair rates and low operative morbidity and mortality [1]. Current international guidelines all advise mitral valve repair (MVR) for symptomatic patients with severe MR. [2, 3]

MR occurs because the two leaflets normally involved in sealing the mitral valve to retrograde flow may not coapt properly. MVR, therefore, comprises restoration of leaflet coaptation and the implantation of standardised annuloplasty rings $[4,5]$. Annuloplasty has been shown to improve valve repair durability and stabilise the entire posterior mitral annulus $[6,7]$. Although various annuloplasty devices are available including flexible vs. semirigid vs. rigid, incomplete vs. complete, planar vs. saddle-shaped and adjustable vs. non-adjustable, there is a lack of sufficiently powered data on the relative merits of each ring design $[4,5,8,9]$.

It was for this reason that we retrospectively gathered the patient and procedural characteristics of patients undergoing mitral valve repair in our clinic. As we almost exclusively use only two different ring types, we focused our analysis on the flexible, C-shaped open Cosgrove Edwards and the semi-rigid closed CarpentierEdwards Physio / Physio II annuloplasty rings. The aim of this analysis was to compare the long-term outcomes.

\section{Patients and methods}

This study is a single-centre, retrospective analysis of mitral valve surgeries performed between January 2005 and December 2015. The study was approved by the site's ethical committee and complied with the Declaration of Helsinki. Written, informed consent was not required due to the use of anonymised data already collected as part of routine practice.

\section{Patient population}

Patients undergoing mitral valve repair were included. Patients had to undergo annuloplasty ring implantation using either the flexible, C-shaped open Cosgrove Edwards flexible band (termed open annuloplasty or OA group) or the semi-rigid closed Carpentier-Edwards Physio / Physio II device (termed closed annuloplasty or CA group). Both devices (OA vs. CA) were used by all surgeons involved depending on the clinical situation. While there is a potential preference of either device type by surgeon, the degree of which was not documented. Potential concomitant procedures were tricuspid valve reconstruction, ablation of AF, left atrial appendage closure and ASD or PFO closure. Patients undergoing first- line mitral valve replacement, patients receiving other ring types and those undergoing concomitant coronary artery bypass graft or aortic valve surgery were excluded. Follow-up data concerning complications and echocardiographic parameters were collected at the patient's last FU visit.

\section{Endpoints of interest}

We defined the following endpoints of interest for our analysis: 1) Survival, 2) freedom from reoperation, 3) the degree of postoperative MR, 4) the postoperative functional status based on the NYHA class, 5) the postoperative left ventricular ejection fraction (LVEF), and 6) the postoperative left ventricular enddiastolic diameter (LVEDD) / left ventricular endsystolic diameter (LVESD).

\section{Statistics}

Data were analysed using descriptive statistics, with categorical variables presented as absolute values and frequencies (\%) and the continuous variables presented as the median and interquartile range (IQR). Comparisons between the $\mathrm{OA}$ and $\mathrm{CA}$ groups were carried out using Mann-Whitney U-test for continuous variables and a Fisher's exact or Chi-square test for categorical variables. Odds ratios (OR) were calculated by logistic regression and adjusted for the key baseline variables age, pulmonary hypertension, prior aortic valve replacement (AVR), LVEDD, LVESD, left/ right atrium $(\mathrm{mm})$, chordae elongation and logistic EuroSCORE. Survival analysis data was presented as Kaplan-Meier curves. In addition, hazard ratios (HR) were calculated by COX-regression and again adjusted for differences in the key baseline variables named above. In all multivariable analyses, only data of patients with available values for all variables taken into account for adjustment were included.

A two-tailed $p$-value of $<0.05$ was considered statistically significant. All statistical tests were performed using IBM SPSS Statistics software version 24.0 (IBM Corporation, Armonk, NY, USA).

\section{Results}

A total of 1357 patients were documented. Patients undergoing direct MVR $(n=201)$ and those receiving other annuloplasty rings than the Cosgrove-Edwards or the Carpentier-Edwards Physio/Physio II $(n=36)$ as part of their MVR were excluded. Of the remaining 1120 patients 528 were assigned to the OA group and 592 patients to the CA group (Fig. 1).

\section{Patient characteristics}

Patients had a median age of 64.0 years and $41.1 \%$ were female (Table 1). Hypertension was a frequent risk factor 


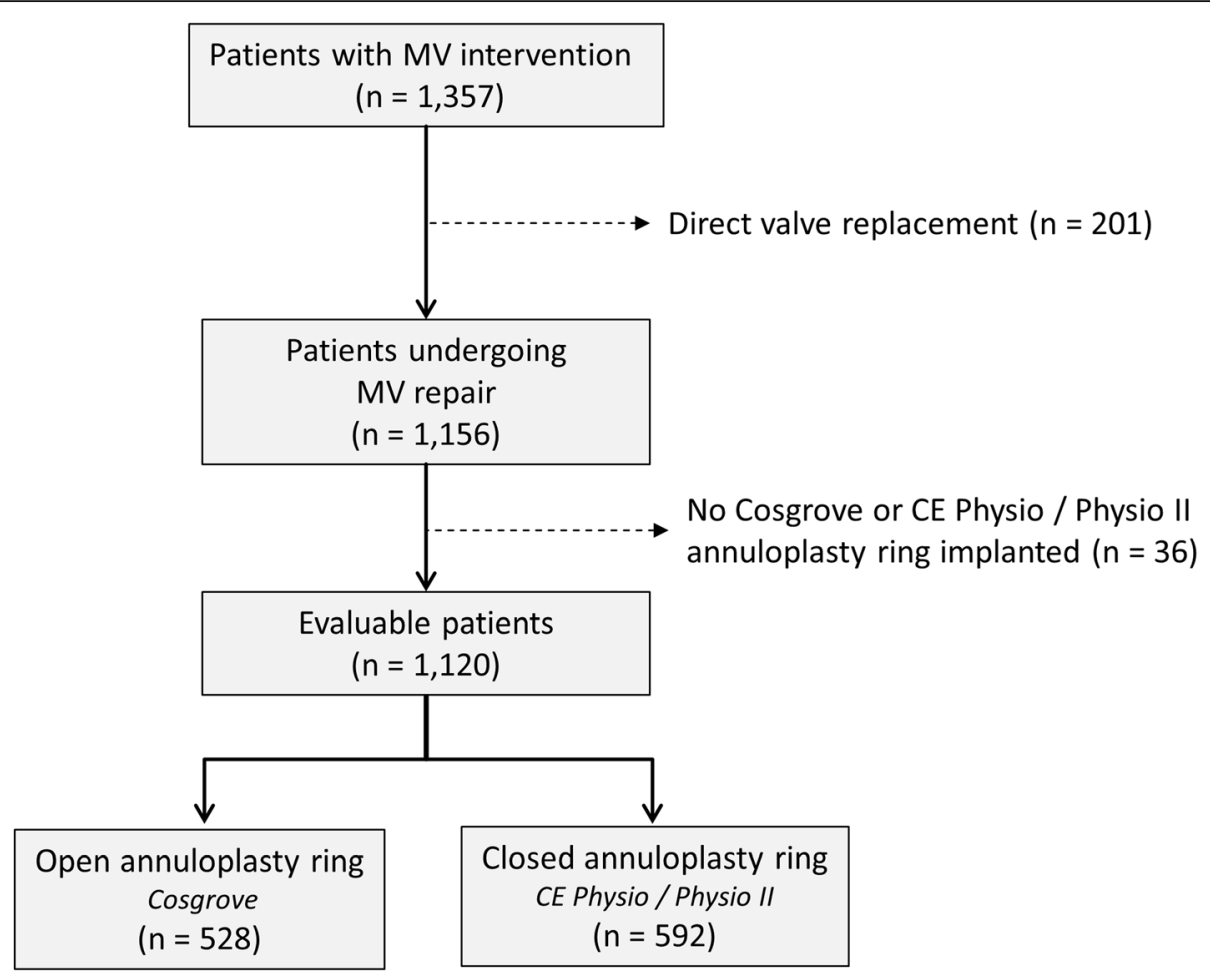

Fig. 1 Flow chart outlining study patient cohorts. Legend: none

(53.1\%); diabetes (7.1\%) and COPD (11.1\%) were frequent comorbid conditions. Disease conditions associated with a causal relationship to mitral valve (MV) disease were pulmonary hypertension (10.0\% of patients) and AF (29.7\%). Overall, $73.6 \%$ of patient had NYHA III/IV defined symptoms. The median logistic EuroSCORE was 3.3\%.

More patients in the OA group had prior aortic valve replacement ( 2.5 vs. $0.8 \% ; p=0.032)$ and a higher logistic EuroSCORE I (3.5 vs. 3.0\%; $\mathrm{p}=0.032$ ) (Table 1 ).

\section{Mitral valve surgery}

The majority of patients in both groups underwent mitral valve repair because of a degenerated valve (92.6 in the OA vs. $93.5 \%$ in the CA groups; $p=0.523$ ) (Table 2). There were echocardiographic differences between groups including a lower left (median 52.0 vs. $55.0 \mathrm{~mm}$; $p=0.002)$, right atrial diameter $(45.0$ vs. $47.0 \mathrm{~mm} ; p=$ 0.016 ) and a reduced mitral opening (median 3.7 vs. 4.1 $\mathrm{mm} ; p=0.021$ ) in the OA group.

Fewer patients receiving $\mathrm{OA}$ had minimal invasive valve surgery $(p<0.001)$ and AML reconstruction $(\mathrm{p}<$ 0.001 ) and the inserted annuloplasty rings generally had a smaller size (Table 2). PML quadrangular resection was more common with OA $(23.3 \%$ vs. $12.3 \%$; $\mathrm{p}<0.001)$, while neo-chordae AML were more common with CA
(15.2\% vs. $8.9 \% ; p=0.001)$ as was cleft plicature $(28.2 \%$ vs. $14.2 \%$; $<0.001$ ). Concomitant procedures (including atrial fibrillation (AF) cryoablation, left atrial appendage (LAA) closure and tricuspid valve repair) were comparable in both groups. The number of patients requiring patent foramen ovale (PFO) closures, however, was higher in the OA group. The cardio-pulmonary bypass time as well as the overall procedure time was shorter in the OA group.

There was a high rate of successful repair reaching $88.4 \%$ in the OA and $90.5 \%$ in the CA group ( $p=0.253)$. Only 8 patients undergoing minimal invasive surgery in either group were converted to median sternotomy (2.2\%). Pleural effusion was $1.7 \%$ in the OA group and $2.7 \%$ in the CA group multivariable adjusted OR 0.34 (95\%CI: 0.12-0.99).

\section{Functional outcomes}

The median MV gradient in patients receiving an OA was 4.0 at both the baseline and follow-up (FU) visit, whereas it was reduced from 4.0 to 3.1 at FU in patients with CA. Thus, the median gradient was significantly different between both groups at the mean 6.1 year FU $(p=0.048)$ (Fig. 2a) which was a potential result of greater ring sizes in the CA group $(p<0.001)$. The 
Table 1 Patient characteristics

\begin{tabular}{|c|c|c|c|c|}
\hline & \multirow{2}{*}{$\begin{array}{l}\text { Total } \\
N=1120^{\text {a }} \\
\% \text { or Median [IQR] }\end{array}$} & \multirow{2}{*}{$\begin{array}{l}\mathrm{OA} \\
N=528^{\text {a }} \\
\% \text { or Median [IQR] }\end{array}$} & $\begin{array}{l}\mathrm{CA} \\
N=592^{a}\end{array}$ & \multirow[t]{2}{*}{$\begin{array}{l}\text { p-value } \\
\text { OA vs. CA }\end{array}$} \\
\hline & & & $\%$ or Median [IQR] & \\
\hline Age in years & $64.0[54.0-73.0]$ & $66.0[55.0-74.0]$ & $63.0[54.0-72.0]$ & 0.060 \\
\hline Female gender, $\%$ & 41.1 & 42.2 & 40.0 & 0.455 \\
\hline BMI $\left(\mathrm{kg} / \mathrm{m}^{2}\right)^{\mathrm{b}}$ & $25.8[23.1-28.7]$ & $26.1[23.5-29.0]$ & $25.6[22.9-28.4]$ & 0.035 \\
\hline \multicolumn{5}{|l|}{ CV risk factors } \\
\hline Hypertension, \% & 53.1 & 52.5 & 53.7 & 0.675 \\
\hline Dyslipidemia, \% & 16.0 & 15.0 & 16.9 & 0.386 \\
\hline \multicolumn{5}{|l|}{ Comorbidities general } \\
\hline Diabetes mellitus, \% & 7.7 & 8.3 & 7.1 & 0.437 \\
\hline Creatinine $(\mathrm{mg} / \mathrm{dL})$ & $0.9[0.7-1.0]$ & $0.9[0.7-1.0]$ & $0.9[0.7-1.1]$ & 0.773 \\
\hline Kidney failure (Crea. > 2.26 mg/dL), \% & 1.6 & 2.3 & 1.0 & 0.094 \\
\hline Stroke, \% & 4.2 & 4.9 & 3.5 & 0.251 \\
\hline COPD, \% & 11.1 & 11.0 & 11.1 & 0.931 \\
\hline$P A D, \%$ & 2.4 & 3.0 & 1.9 & 0.202 \\
\hline \multicolumn{5}{|l|}{ Comorbidity cardiac } \\
\hline$A F, \%$ & 29.7 & 28.1 & 31.2 & 0.257 \\
\hline$C A D, \%$ & 8.7 & 8.5 & 8.8 & 0.877 \\
\hline Prior MI ( $\leq 90$ days), $\%$ & 0.4 & 0.4 & 0.5 & 1.000 \\
\hline Prior $C A B G, \%$ & 2.9 & 2.8 & 2.9 & 0.975 \\
\hline Prior aortic valve replacement, $\%$ & 1.6 & 2.5 & 0.8 & 0.032 \\
\hline Prior pacemaker, \% & 1.6 & 1.5 & 1.7 & 0.815 \\
\hline NYHA class III/IV, \% & 73.6 & 75.1 & 72.3 & 0.281 \\
\hline CCS class III/IV, \% & 3.8 & 4.7 & 3.0 & 0.141 \\
\hline Pulmonary hypertension, $\%$ & 10.0 & 11.6 & 8.6 & 0.104 \\
\hline Emergency indication for surgery, \% & 1.8 & 2.1 & 1.5 & 0.482 \\
\hline Log EuroSCORE I, \% & $3.3[1.6-7.1]$ & $3.5[1.7-8.0]$ & $3.0[1.5-6.6]$ & 0.032 \\
\hline
\end{tabular}

${ }^{a}$ As data are largely complete, e.g., maximum of 3 out of 1120 variables missing for single variables we omitted to name the number of patients available for each variable

${ }^{b}$ For BMI there is only data for 896 patients ( 418 with OA/ 478 with CA)

$A F$ atrial fibrillation, $B M I$ body mass index, $C A B G$ coronary artery bypass graft, $C A D$ coronary artery disease, CCS Canadian Cardiovascular Society, COPD chronic obstructive pulmonary disease, Crea. Creatinine, CV cardiovascular, MI myocardial infarction, NYHA New York Heart Association

proportion of patients with $\mathrm{II}^{\circ}$ or $\mathrm{III}^{\circ} / \mathrm{IV}^{\circ}$ grade mitral insufficiency was strongly reduced after the intervention and at 6.1 years with no difference between the OA and CA patient groups (Fig. 2b). Postoperative Systolic Anterior Motion was observed in 52 out of 1120 patients with no statistically significant difference between groups (OA $4.4 \%$ vs. CA $4.9 \% ; p=0.667$ ). There was, however, a noteworthy trend with higher rates of $\mathrm{I}^{\circ}$ degree mitral insufficiency at 6.1 years FU compared with the immediate postoperative period.

The LVEF dropped from a median baseline value of $60 \%$ (e.g. pre-intervention) to a median LVEF of $55 \%$ post-procedurally. There were no differences in the LVEF at baseline $(p=0.660)$ or after the intervention $(p=0.316)$ between groups. LVEF recovered later on (5.8 years) back to the baseline value of $60 \%$ which was identical in both groups $(p=0.906)$ (Fig. 3a). LVEDD was $55 \mathrm{~mm}$ in the OA group and $56 \mathrm{~mm}$ in the CA group at baseline and $50 \mathrm{~mm}$ in both groups at the follow-up. While their difference at baseline was statistically significant $(p=0.003)$, it was not at the follow-up (Fig. 3b). LVESD was 35 $\mathrm{mm}$ and $36 \mathrm{~mm}$, respectively at baseline $(p=0.001)$ and $37 \mathrm{~mm}$ at the follow-up in either group ( $p=$ $0.559)$.

In agreement with the decrease in mitral valve insufficiency at a preserved LVEF, there was a considerable improvement of symptoms observed with the 
Table 2 MV pathology and echocardiographic parameters and procedural details

\begin{tabular}{|c|c|c|c|}
\hline & $O A(n=528)$ & $C A(n=592)$ & \\
\hline & $\%$ & $\%$ & $\mathrm{p}$-value \\
\hline \multicolumn{4}{|l|}{ MV pathologies } \\
\hline Functional & 7.4 & 6.4 & 0.523 \\
\hline Degenerative & 92.6 & 93.5 & \\
\hline Acute endocarditis & 2.5 & 1.9 & 0.486 \\
\hline Annulus dilatation & 94.9 & 96.6 & 0.148 \\
\hline Annulus calcification & 3.6 & 4.1 & 0.692 \\
\hline AML prolapse & 19.1 & 23.6 & 0.066 \\
\hline AML flail & 5.1 & 6.8 & 0.247 \\
\hline PML prolapse & 71.4 & 68.9 & 0.365 \\
\hline PML flail & 51.7 & 46.6 & 0.089 \\
\hline Chordae elongation & 22.5 & 28.4 & 0.025 \\
\hline Restrictive leaflet & 3.0 & 3.4 & 0.742 \\
\hline MV stenosis & 0.6 & 0.3 & 0.671 \\
\hline MV insufficiency $\geq$ grade II & 99.6 & 99.3 & 0.690 \\
\hline Echocardiographic parameters & Median [IQR] & Median [IQR] & \\
\hline LVEF, \% & $60.0[55.0-63.0]$ & $60.0[55.0-64.0]$ & 0.660 \\
\hline LVEDD (mm) & $55.0[51.0-59.0]$ & $56.0[52.0-60.0]$ & 0.003 \\
\hline LVESD (mm) & $35.0[31.0-39.0]$ & $36.0[32.0-41.0]$ & 0.001 \\
\hline Left atrial diameter (mm) & $52.0[46.0-59.0]$ & $55.0[47.0-63.0]$ & 0.002 \\
\hline Right atrial diameter (mm) & $45.0[38.0-52.0]$ & $47.0[39.0-53.0]$ & 0.016 \\
\hline Mitral opening (mm) & $3.7[3.1-4.6]$ & $4.1[3.4-4.8]$ & 0.021 \\
\hline PISA radius (mm) & $1.0[1.0-1.3]$ & $1.2[1.0-1.4]$ & 0.128 \\
\hline Vena contracta (mm) & $7.0[5.0-8.0]$ & $7.0[5.0-7.0]$ & 0.397 \\
\hline Procedural details & $\%$ & $\%$ & \\
\hline Operative approach & & & $<0.001$ \\
\hline MIC & 59.1 & 71.3 & \\
\hline CS & 40.9 & 28.7 & \\
\hline \multicolumn{4}{|l|}{ Mitral valve repair } \\
\hline Triangular resection PML & 16.7 & 15.7 & 0.664 \\
\hline Quadr. resection PML & 23.3 & 12.3 & $<0.001$ \\
\hline AML reconstruction & 12.3 & 22.6 & $<0.001$ \\
\hline PML reconstruction & 75.4 & 72.1 & 0.218 \\
\hline Neo chordae AML & 8.9 & 15.2 & 0.001 \\
\hline Neo chordae PML & 29.9 & 35.3 & 0.056 \\
\hline Cleft plicatur & 14.2 & 28.2 & $<0.001$ \\
\hline Annuloplasty ring size & & & $<0.001$ \\
\hline $26-28$ & 36.4 & 15.4 & \\
\hline $30-32$ & 40.4 & 38.9 & \\
\hline $34-36$ & 20.9 & 39.1 & \\
\hline $38-40$ & 2.3 & 6.4 & \\
\hline \multicolumn{4}{|l|}{ Concomitant procedures } \\
\hline Cryoablation & 25.8 & 28.7 & 0.276 \\
\hline LAA closure & 26.7 & 24.0 & 0.296 \\
\hline
\end{tabular}


Table 2 MV pathology and echocardiographic parameters and procedural details (Continued)

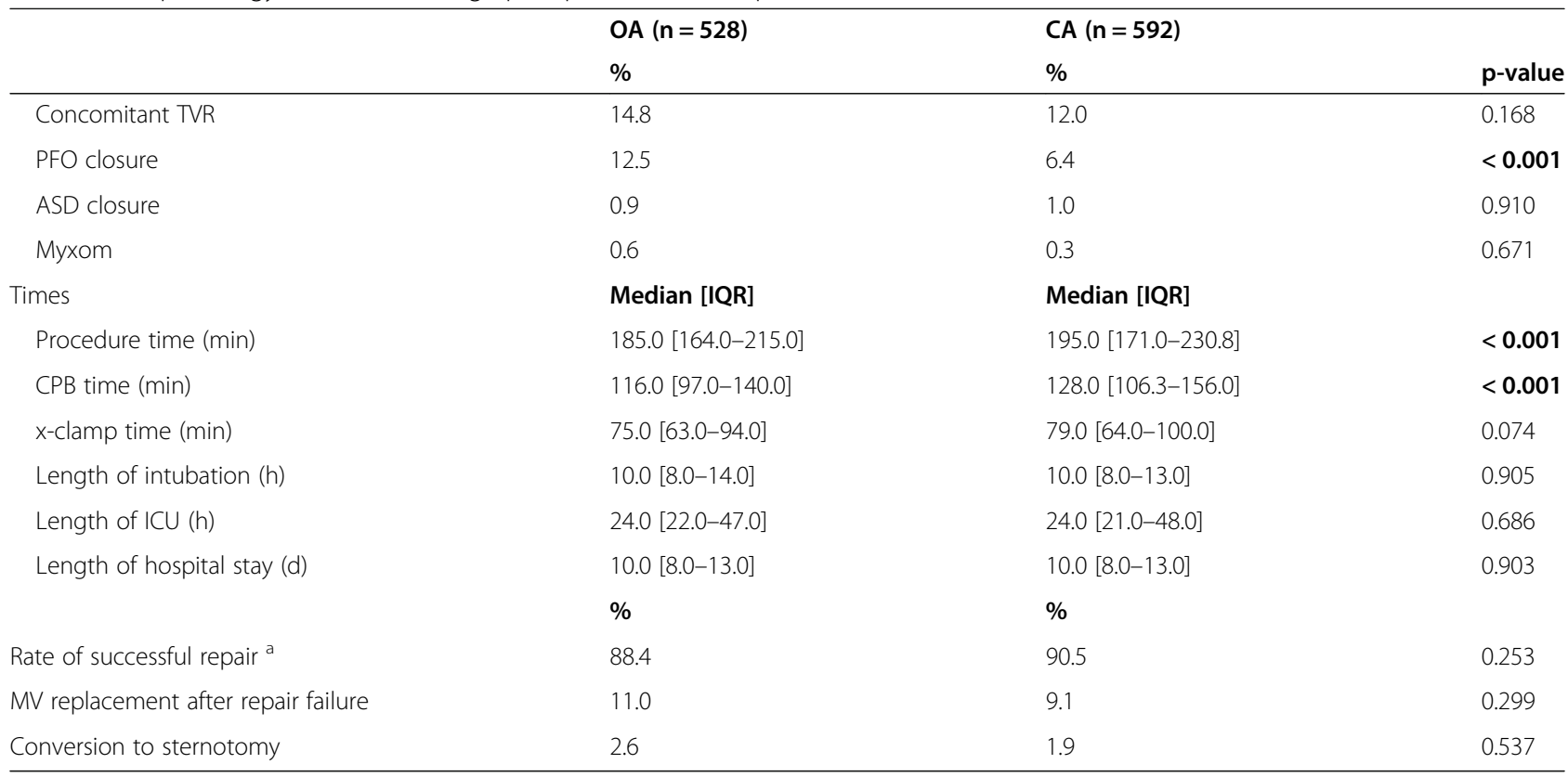

$A M L$ anterior mitral valve leaflet, $A S D$ atrial septal defect, $C P B$ cardiopulmonary bypass, CS conventional sternotomy, ICU intensive care unit, IQR interquartile range, $L A A$ left atrial appendage closure, $L V E D D$ left ventricular enddiastolic diameter, $L V E F$ left ventricular ejection fraction, $L V E S D$ left ventricular endsystolic diameter, MIC minimally invasive mitral valve surgery, MV mitral valve, PFO patent foramen ovale, PISA proximal isovelocity surface area, PML posterior mitral valve leaflet, TVR tricuspidal valve repair

${ }^{a} 5$ patients were removed as they died within $72 \mathrm{~h}$ after the intervention (electromechanical decoupling $\mathrm{n}=1$, right ventricular failure $\mathrm{n}=1$, low cardiac output $\mathrm{n}=2$, cardiogenic shock and kidney failure $n=1$ )

majority of patients being NYHA I or II at 6.3 years (Fig. 4) with no difference between groups $(p=$ $0.133)$.

\section{Hard outcomes}

The rates of re-intervention following the immediate post-procedural phase and up to 30 days was $0.6 \%$ in the $\mathrm{OA}$ and $0.5 \%$ in the CA group (adjusted OR $0.97 ; 95 \% \mathrm{CI}$ 0.17 to 5.47 ).

Immediate within $72 \mathrm{~h}$ procedural mortality affected 7 out of 1120 patients (0.6\%). Outcomes at 30 days showed comparable rates for all-cause death, stroke, acute renal failure, MI and pacemaker between groups (Table 3). An initial significant difference in the rate of non-CV death disappeared upon adjustment for differences in baseline characteristics (adjusted OR 5.00; 95\%CI 0.52-48.28). Long-term mortality was comparable between patients in the $\mathrm{OA}$ and $\mathrm{CA}$ groups, with an estimated 10-year survival of 77.7 and $74.4 \%$ for patients, respectively (log rank $p=0.300$; adj. HR $0.926 \quad(95 \% \mathrm{CI}: \quad 0.642-1.3135 ; \quad p=0.681)$ (Fig. 5).

\section{Discussion}

In our dataset of 1156 MVR procedures, we almost exclusively used the open Cosgrove-Edwards and the closed Carpentier-Edwards Physio/Physio II in patients with degenerative valve disease. Rates of successful repair were about $90 \%, 72 \mathrm{~h}$ procedural mortality was $0.6 \%$ and the rate of re-intervention was $0.6 \%$ within the first 30 days. Functional as well as hard outcomes with both ring types were largely comparable, with a slightly higher MV gradient seen with time in the CA group.

To the best of our knowledge, our dataset is the largest study with the longest follow-up so far comparing the use of open and closed annuloplasty rings for the treatment of MR. The majority of the patients experienced substantial improvement of their mitral insufficiency and symptom status. Interestingly, at 6.1 years, there was a slight worsening in the degree of mitral valve insufficiency with an increase in $I^{\circ} \mathrm{MR}$. It is reassuring though, that $\mathrm{III}^{\circ}$ and $\mathrm{IV}^{\circ}$ degree MR was not observed during our long-term follow-up giving confidence that the procedure achieved its clinical goals.

In an attempt to quantify potential differences between different annuloplasty rings, Khamooshian et al. performed a secondary data analysis [10]. They clustered the large number of more than 37 available rings into 3 groups of flexible, semi-rigid and rigid rings and focused on patients with either 


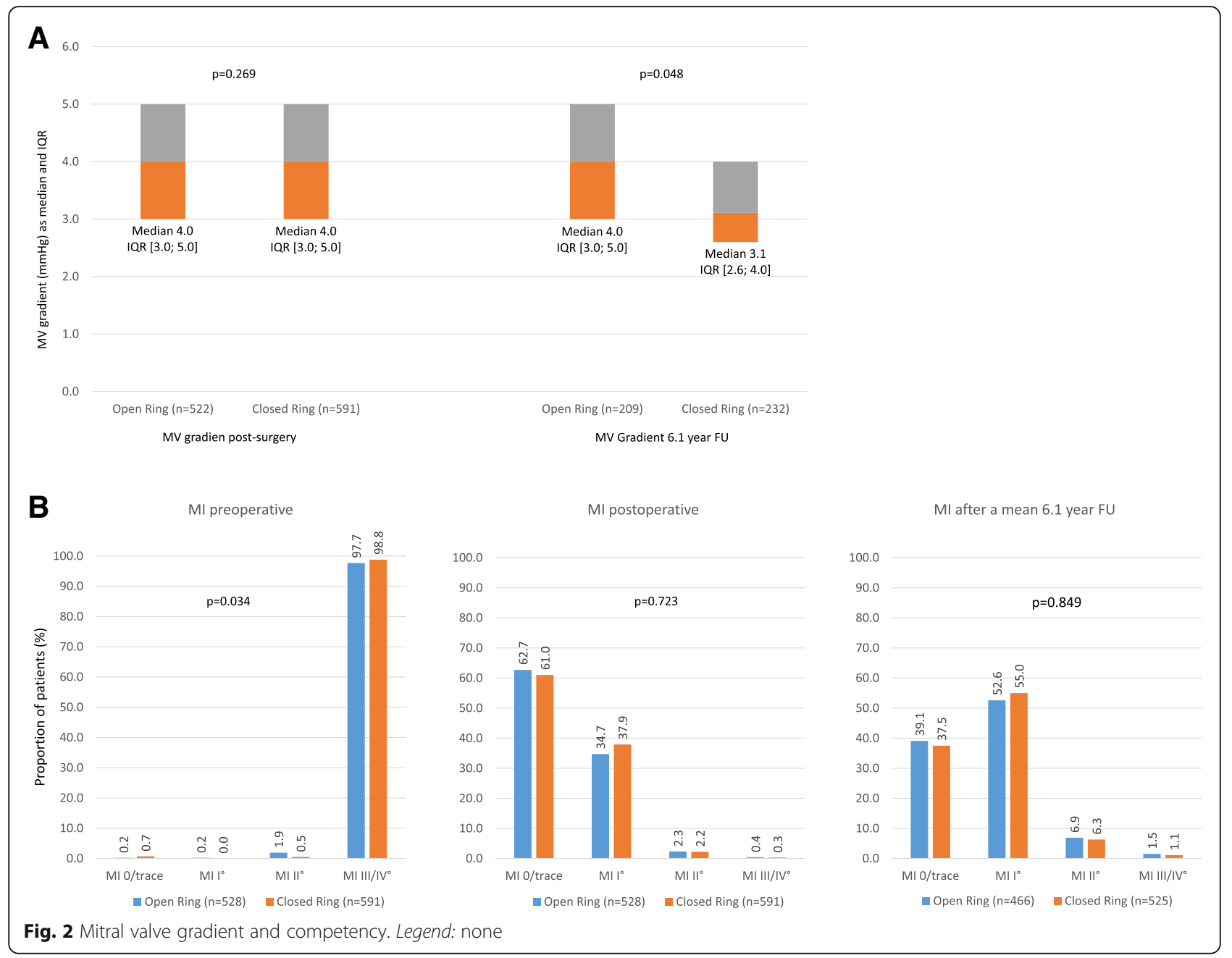

degenerative etiology or those patients with ischemic / dilated cardiomyopathy. They found that irrespective of the ring used, the LVEF remained unchanged after the intervention (just as in our analysis), the LVESD decreased with the use of all ring types, and LVEDD only decreased with the use of flexible and rigid rings, while there was no decrease associated with semi-rigid rings. We observed a decrease in both $\mathrm{OA}$ (with the flexible ring) and $\mathrm{CA}$ groups (with the semi-rigid ring), with no nominal difference between groups. The drop is unlike as in the Khamooshian analysis. LVESD was essentially unchanged at the follow-up.

A Pubmed search of the available literature over the last 10 years in June 2019, the keywords "annuloplasty, mitral, ring, comparison" resulted in a total of 41 references, of which seven actually presented a comparison of at least two different rings (1 animal model [11], 2 restricted to ischemic etiology [12-14] and 4 which did not specify the etiology $[15,16]$ as well as one computer-based modelling study [17]). The majority of these did not report on long-term functional and survival benefits, but focused on shortterm hemodynamic results. Nishi [15] et al. found, that using the Cosgrove $(n=10)$, Sorin-Memo 3D $(n=17)$ and CE Physio II $(n=7)$ implantation rings, all controlled mitral regurgitation well, the Cosgrove more than the Sorin-Memo more than the CE Physio II had a dynamic diastolic to systolic change in mitral annular diameter during the cardiac cycle. Tsuneto [16] et al. reported from 31 patients, that the Cosgrove was found to be more flexible, while the SorinMemo ring maintained the elliptical shape more efficiently. Bouchez [18] et al. reported in a comparison of the CE Physio II $(n=17)$ with the Memo 3D $(n=$ 16) that the mitral annulus dynamics after annuloplasty with the Physio II and Memo 3D rings demonstrated a better systolic 3D restoration of the saddle shape with the Physio II ring, whereas the saddleshaped geometry improved significantly with the 

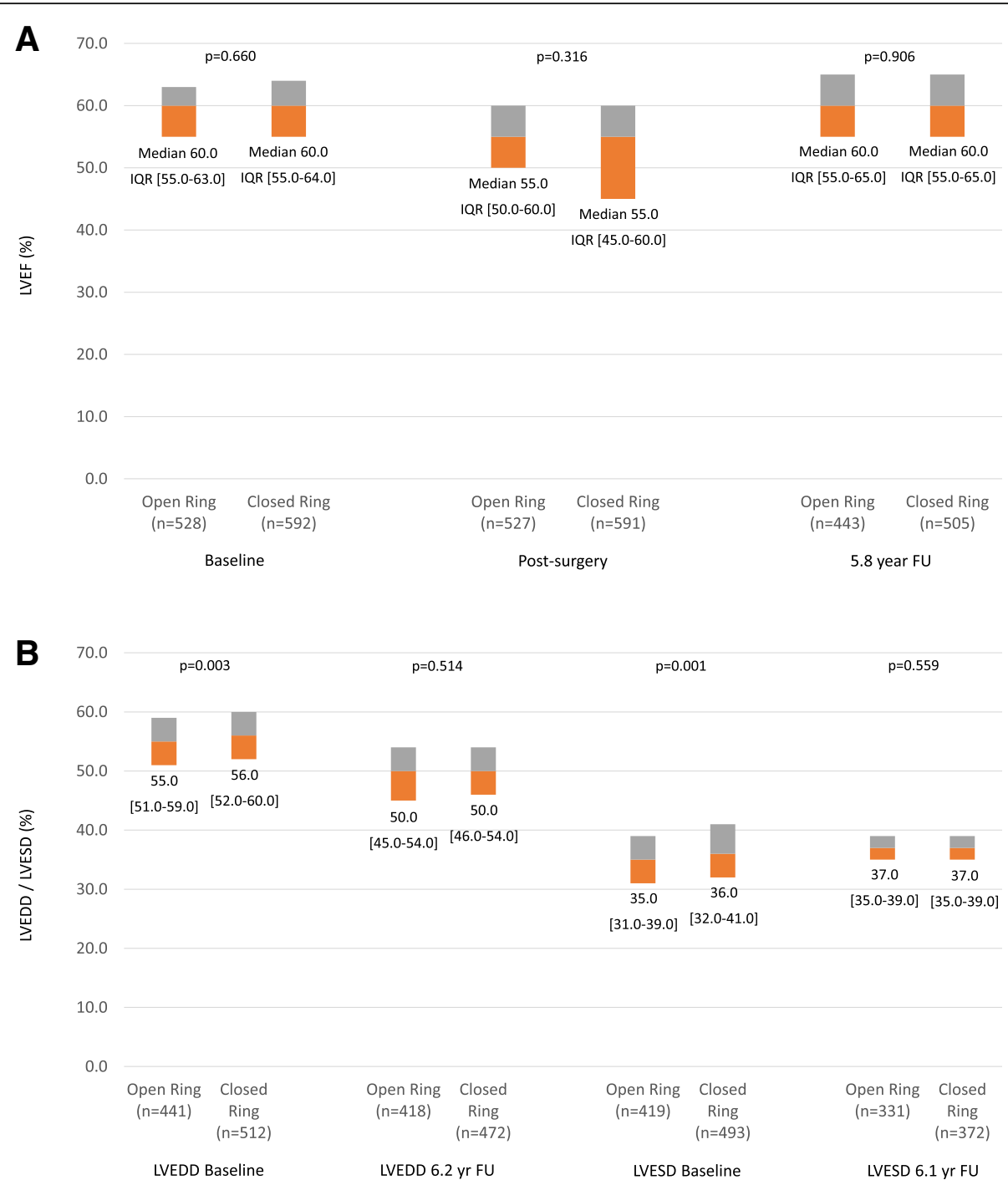

Fig. 3 Left Ventricular Dimension and Function. Legend: none

Memo 3D ring, as a dynamic phenomenon. The Memo 3D ring also showed increased anteroposterior annular mobility and folding dynamics throughout the cardiac cycle.

Silberman [13] et al. was the only to report on longer-term clinical outcomes in his report of 169 patients with ischemic MR. The symptom status (NYHA) was class III / IV in 33\% with the flexible ring and $14 \%$ with the rigid ring ( $p=0.03$, MR grade was 1.15 and $0.7(p=0.006)$, respectively. There was no difference in LV function or dimensions. At follow-up, 29 patients (34\%) in the flexible group had residual MR of moderate degree or greater compared with $6(15 \%)$ in the rigid group $(p=0.03)$. Late mortality was observed in 32 out of 117 patients, which affected exclusively the flexible group (FU 58 months in the flexible and 14 months in the rigid group). Although these data on ischemic MR are reported on the same outcome, their quantity is hard to compare to our results as our database was exclusively built on degenerative mitral disease.

\section{Limitations}

There were several limitations to this study. Firstly, due to its retrospective nature, data for certain fields may have been missing. Secondly, there were baseline differences between OA and CA groups, representing a possible source of bias. Thirdly, in the multivariate analyses, only data of patients with available values for all variables were taken into account for adjustment purposes (no imputation). Finally, major complications and echocardiography data were collected at the patient's last FU visit - this data was not available for some patients as 


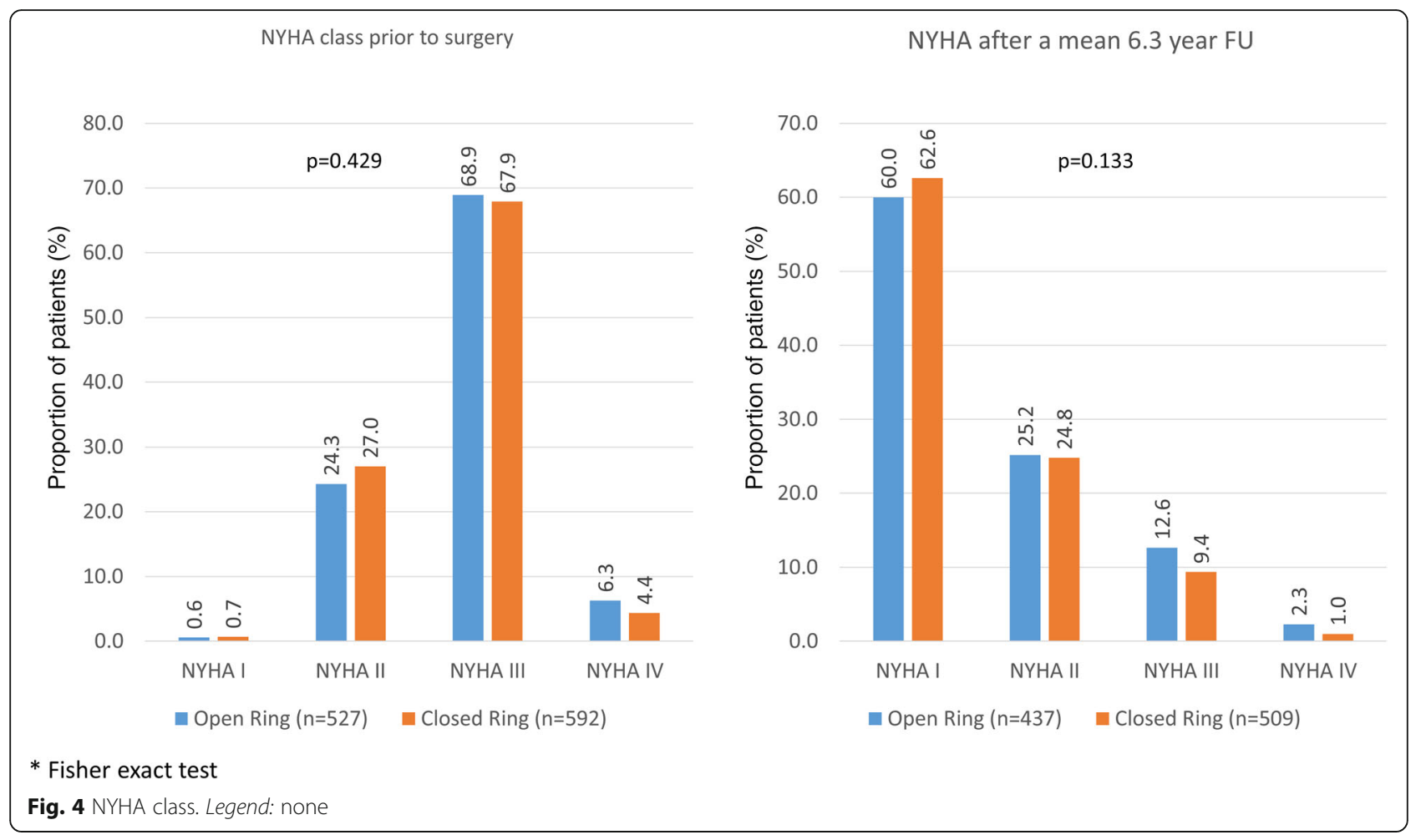

Table 3 Procedure-related complications and 30-day outcomes

\begin{tabular}{|c|c|c|c|c|}
\hline & $\begin{array}{l}\mathrm{OA}(\%) \\
\mathrm{N}=528\end{array}$ & $\begin{array}{l}\text { CA (\%) } \\
N=592\end{array}$ & $\begin{array}{l}\text { Unadjusted OR } \\
95 \% \mathrm{Cl}\end{array}$ & $\begin{array}{l}\text { Adjusted OR }{ }^{\mathrm{a}} \\
95 \% \mathrm{Cl}\end{array}$ \\
\hline \multicolumn{5}{|l|}{ Procedure related complications } \\
\hline Immediate $72 \mathrm{~h}$ procedural mortality & 0.9 & 0.3 & $2.82(0.5514 .60)$ & $1.42(0.21-9.70)$ \\
\hline MVI $\geq$ II post op & 2.7 & 2.5 & $1.05(0.50-2.19)$ & $0.70(0.28-1.73)$ \\
\hline Wound infection & 1.1 & 1.7 & $0.67(0.24-1.85)$ & $0.28(0.06-1.38)$ \\
\hline Pericardial tamponade & 3.6 & 2.4 & $1.54(0.77-3.11)$ & $1.48(0.58-3.77)$ \\
\hline AV block grade III & 6.3 & 5.4 & $1.17(0.71-1.93)$ & $0.98(0.54-1.81)$ \\
\hline Pneumonia & 5.1 & 3.5 & $1.47(0.82-2.62)$ & $1.22(0.59-2.54)$ \\
\hline Pneumothorax & 0.6 & 1.4 & $0.42(0.11-1.58)$ & $0.60(0.15-2.48)$ \\
\hline Pleural effusion & 1.7 & 2.7 & $0.63(0.27-1.43)$ & $0.34(0.12-0.99)$ \\
\hline AF & 16.9 & 15.7 & $1.01(0.79-1.50)$ & $1.05(0.71-1.55)$ \\
\hline \multicolumn{5}{|l|}{ 30-day outcomes } \\
\hline Death & 3.6 & 2.0 & $1.80(0.87-3.75)$ & $1.16(0.45-2.96)$ \\
\hline Cardiovascular death & 1.9 & 1.7 & $1.12(0.46-2.72)$ & $0.73(0.24-2.24)$ \\
\hline Non-CV death & 1.7 & 0.3 & $5.12(1.10-23.78)$ & $5.00(0.52-48.28)$ \\
\hline Stroke & 3.6 & 3.4 & $1.07(0.56-2.02)$ & $0.91(0.43-1.89)$ \\
\hline Acute renal failure & 6.3 & 5.1 & $1.30(0.78-2.17)$ & $0.97(0.49-1.91)$ \\
\hline Myocardial infarction & 0.4 & 0.7 & $0.56(0.10-3.06)$ & $0.66(0.11-4.15)$ \\
\hline Pacemaker implantation & 6.8 & 6.3 & $1.10(0.68-1.77)$ & $0.91(0.51-1.60)$ \\
\hline Re- MV surgery & 0.6 & 0.5 & $1.12(0.22-5.58)$ & $0.97(0.17-5.47)$ \\
\hline
\end{tabular}

$A F$ atrial fibrillation, $A V$ atrioventricular, $C V$ cardiovascular, $M V$ mitral valve, $M V I$ mitral valve insufficiency

${ }^{a}$ ORs were calculated by logistic regression and adjusted for age, pulmonary hypertension, prior AVR, LVEDD, LVESD, left/right atrium (mm), chordae elongation and $\log$ EuroScore. In the multivariate analysis only data of patients with available values for all variables taken into account for adjustment were included ( $n=$ 897). No BMI or mitral opening data were considered as there was a considerable degree of missing values 


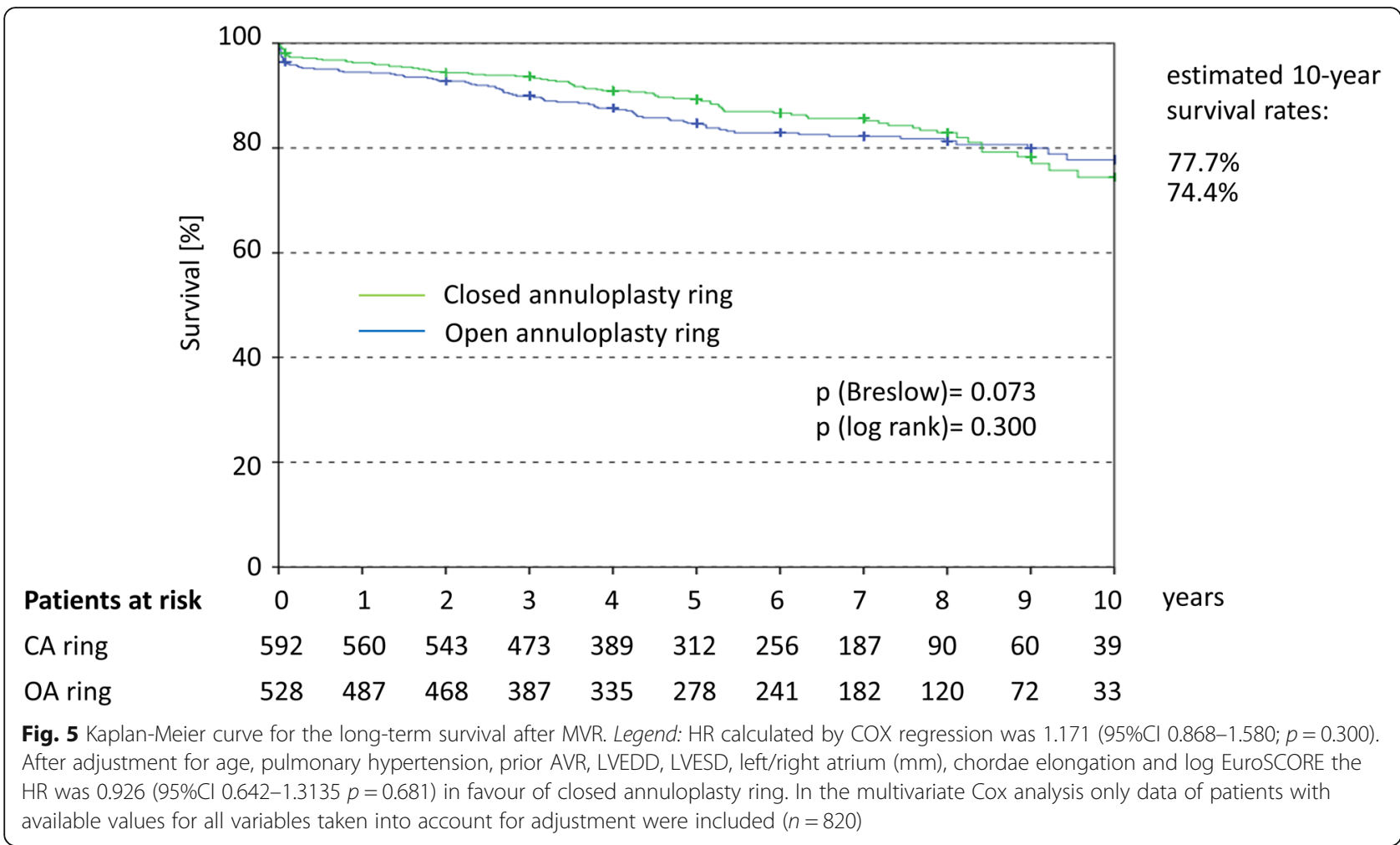

they only recently received their implant and it also excluded data for those patients lost to FU.

\section{Conclusions}

In summary, our study showed that the use of OA and $C A$ rings for the treatment of patients undergoing mitral valve repair were comparable, with both types of rings reducing mitral insufficiency and improving NYHA scores immediately after treatment, as well as at 30-days and $\sim 6$ years after treatment. Whether this means these rings are interchangeable or a carefully selection of the best-for-the-patient devices will be subject of future investigations.

\footnotetext{
Abbreviations

AF: Atrial fibrillation; AML: Anterior mitral valve leaflet; ASD: Atrial septal defect; AV: Atrioventricular; CA: Closed annulopasty; CABG: Coronary artery bypass graft; CAD: Coronary artery disease; CCS: Canadian Cardiovascular Society; COPD: Chronic obstructive pulmonary disease;

CPB: Cardiopulmonary bypass; CS: Conventional sternotomy; CV: Cardiovascular; HR: Hazard Ratio; ICU: Intensive care unit; IQR: Interquartile range; LAA: Left atrial appendage; LVEDD: Left ventricular end-diastolic pressure; LVEF: Left ventricular ejection fraction; LVESD: Left ventricular end-systolic pressure; MIC: Minimally invasive mitral valve surgery; MV: Mitral valve; MVI: Mitral valve insufficiency; MVS: Mitral valve surgery; NYHA: New York Heart Association; OA: Open annulopasty; OR: Odds Ratio; PAD: Peripheral artery disease; PISA: Proximal isovelocity surface area; PFO: Patent foramen ovale; PML: Posterior mitral valve leaflet; TVR: Tricuspid valve repair
}

\section{Acknowledgements}

Not applicable.

\section{Authors' contributions}

$A C, M W, S H, M S$ and MR performed the surgery and collected the data. AC, $\mathrm{KB}, \mathrm{MZ}, \mathrm{OJL}$, and $\mathrm{PB}$ worked on the dataset, designed the analyses and developed the concept. $\mathrm{AC}$ and $\mathrm{PB}$ drafted the manuscript which was critically revised by MW, OJL, MZ, SH, KB, YHC, MS, and MR. All authors approved the final version of the manuscript and can be held accountable for the integrity of the work.

\section{Funding}

Open Access funding enabled and organized by Projekt DEAL.

\section{Availability of data and materials}

Data are available from the corresponding author upon reasonable request.

\section{Declarations}

Ethics approval and consent to participate

The study was approved by the site's ethical committee and complied with the Declaration of Helsinki and its amendments. Given the use of anonymised data already collected as part of routine diagnosis and treatment, written informed consent was not required.

\section{Consent for publication}

Not applicable.

\section{Competing interests}

Peter Bramlage received research funding from Edwards Lifesciences related and unrelated to the present work. The other authors have no conflict of interest to disclose.

\section{Author details}

'Department of Cardiac Surgery, Kerckhoff-Heart Center Bad Nauheim, Campus of the University Hospital Giessen, Justus-Liebig Universiy Giessen, Benekestraße 2-8, 61231 Bad Nauheim, Germany. ${ }^{2}$ Institute for Pharmacology and Preventive Medicine, Cloppenburg, Germany. 
Received: 7 August 2020 Accepted: 8 March 2021

Published online: 20 March 2021

\section{References}

1. Vahanian A, Alfieri O, Andreotti F, Antunes MJ, Baron-Esquivias G, Baumgartner H, Borger MA, Carrel TP, De Bonis M, Evangelista A, et al. Guidelines on the management of valvular heart disease (version 2012). Eur Heart J. 2012;33(19):2451-96. https://doi.org/10.1093/eurheartj/ehs109.

2. Baumgartner $\mathrm{H}$, Falk V, Bax JJ, De Bonis M, Hamm C, Holm PJ, lung B, Lancellotti P, Lansac E, Rodriguez Munoz D, et al. 2017 ESC/EACTS guidelines for the management of valvular heart disease. Eur Heart J. 2017; 38(36):2739-91. https://doi.org/10.1093/eurheartj/ehx391.

3. Nishimura RA, Otto CM, Bonow RO, Carabello BA, Erwin JP 3rd, Fleisher LA, Jneid H, Mack MJ, McLeod CJ, O'Gara PT, et al. 2017 AHA/ACC focused update of the 2014 AHA/ACC guideline for the Management of Patients with Valvular Heart Disease: a report of the American College of Cardiology/ American Heart Association task force on clinical practice guidelines. Circulation. 2017;135(25):e1159-95.

4. Spiegelstein D, Moshkovitz Y, Sternik L, Fienberg MS, Kogan A, Malachy A, Raanani E. Midterm results of mitral valve repair: closed versus open annuloplasty ring. Ann Thorac Surg. 2010;90(2):489-95. https://doi.org/10.1 016/j.athoracsur.2010.03.070.

5. Vahanian A, Urena M, Ince H, Nickenig G. Mitral valve: repair/clips/cinching/ chordae. Eurolntervention. 2017;13(Aa):Aa22-aa30.

6. Milano A, Codecasa R, De Carlo M, Nardi C, Tartarini G, Verunelli F, Bortolotti U. Mitral valve annuloplasty for degenerative disease: assessment of four different techniques. J Heart Valve Dis. 2000;9(3):321-6.

7. Gillinov AM, Cosgrove DM, Blackstone EH, Diaz R, Arnold JH, Lytle BW, Smedira NG, Sabik JF, McCarthy PM, Loop FD. Durability of mitral valve repair for degenerative disease. J Thorac Cardiovasc Surg. 1998;116(5):73443. https://doi.org/10.1016/S0022-5223(98)00450-4.

8. Chang BC, Youn YN, Ha JW, Lim SH, Hong YS, Chung N. Long-term clinical results of mitral valvuloplasty using flexible and rigid rings: a prospective and randomized study. J Thorac Cardiovasc Surg. 2007;133(4):995-1003. https://doi.org/10.1016/j.jtcvs.2006.10.023.

9. Gatti G, Pugliese P. Preliminary experience in mitral valve repair using the Cosgrove-Edwards annuloplasty ring. Interact Cardiovasc Thorac Surg. 2003; 2(3):256-61. https://doi.org/10.1016/S1569-9293(03)00056-2.

10. Khamooshian A, Buijsrogge MP, de Heer F, Grundeman PF. Mitral valve annuloplasty rings: review of literature and comparison of functional outcome and ventricular dimensions. Innovations (Phila). 2014;9(6):399-415.

11. Konerding MA, Simpanen J, Ihlberg L, Aittomaki J, Werkkala K, Delventhal V, Ackermann M. Comparison of the novel Medtentia double helix mitral annuloplasty system with the Carpentier-Edwards Physio annuloplasty ring: morphological and functional long-term outcome in a mitral valve insufficiency sheep model. J Cardiothorac Surg. 2013;8(1):70. https://doi. org/10.1186/1749-8090-8-70.

12. Fattouch K, Moscarelli M, Castrovinci S, Guccione F, Dioguardi P, Speziale G, Lancellotti P. A comparison of 2 mitral Annuloplasty rings for severe ischemic mitral regurgitation: clinical and echocardiographic outcomes. Semin Thorac Cardiovasc Surg. 2016;28(2):261-8. https://doi.org/10.1053/j. semtcvs.2016.04.007.

13. Silberman S, Klutstein MW, Sabag T, Oren A, Fink D, Merin O, Bitran D. Repair of ischemic mitral regurgitation: comparison between flexible and rigid annuloplasty rings. Ann Thorac Surg. 2009;87(6):1721-6; discussion 1726-1727. https://doi.org/10.1016/j.athoracsur.2009.03.066.

14. Suh YJ, Chang BC, Im DJ, Kim YJ, Hong YJ, Hong GR, Kim YJ. Assessment of mitral annuloplasty ring by cardiac computed tomography: correlation with echocardiographic parameters and comparison between two different ring types. J Thorac Cardiovasc Surg. 2015;150(5):1082-90. https://doi.org/10.101 6/j.jtcvs.2015.07.019.

15. Nishi H, Toda K, Miyagawa S, Yoshikawa Y, Fukushima S, Kawamura M, Yoshioka D, Saito T, Ueno T, Kuratani T, Sawa Y. Annular dynamics after mitral valve repair with different prosthetic rings: a real-time threedimensional transesophageal echocardiography study. Surg Today. 2016; 46(9):1083-90. https://doi.org/10.1007/s00595-015-1279-z.

16. Tsuneto A, Eishi K, Miura T, Tanigawa K, Matsukuma S, Minami T, Koide Y, Ikeda S, Kawano H, Maemura K. Comparison of saddle-shape flexibility and elliptical-shape stability between Cosgrove-Edwards and memo-3D annuloplasty rings using three-dimensional analysis software. Gen Thorac
Cardiovasc Surg. 2016;64(6):325-32. https://doi.org/10.1007/s11748-016-064 $5-0$

17. Al-Maisary S, Engelhardt S, Graser B, Wolf I, Karck M, De Simone R. Computer-based comparison of different methods for selecting mitral annuloplasty ring size. J Cardiothorac Surg. 2017;12(1):8. https://doi.org/1 0.1186/s13019-017-0571-y.

18. Bouchez S, Timmermans F, Philipsen T, Francois K, Bove T. Comparison of the sustainability of mitral annular dynamics between two semi-rigid annuloplasty devices. Eur J Cardiothorac Surg. 2019. https://doi.org/10.1093/ ejcts/ezz035.

\section{Publisher's Note}

Springer Nature remains neutral with regard to jurisdictional claims in published maps and institutional affiliations.
Ready to submit your research? Choose BMC and benefit from:

- fast, convenient online submission

- thorough peer review by experienced researchers in your field

- rapid publication on acceptance

- support for research data, including large and complex data types

- gold Open Access which fosters wider collaboration and increased citations

- maximum visibility for your research: over $100 \mathrm{M}$ website views per year

At BMC, research is always in progress.

Learn more biomedcentral.com/submissions 